\title{
Bioatividade de óleos essenciais no controle de Botrytis cinerea isolado de morangueiro
}

\author{
LORENZETTI, E.R. ${ }^{12^{*}}$; MONTEIRO, F.P. ${ }^{1}$; SOUZA, P.E. ${ }^{1}$; SOUZA, R.J. ${ }^{1}$ SCALICE, H.K. ${ }^{1}$; DIOGO JR, R. ${ }^{1}$; PIRES, \\ M.S.O. ${ }^{1}$ \\ ${ }^{1}$ UFLA - Universidade Federal de Lavras. Campus Universitário. Caixa Postal 3037, 37200-000 Lavras - MG. ${ }^{2}$ \\ Instituto Federal de Educação, Ciência e Tecnologia Sudeste de Minas Gerais - Câmpus Rio Pomba. Av. Dr José \\ Sebastião da Paixão s/n - Bairro Lindo Vale - 36180-000, Rio Pomba - MG. Email para correspondência: \\ elorenzetti@gmail.com
}

\begin{abstract}
RESUMO: Objetivou-se avaliar o uso de óleos essenciais sobre isolados de Botrytis cinerea, causador do mofo cinzento em morangueiro. Foram testados óleos essenciais de capim-limão, palmarosa, citronela, cravo, canela, menta, lavanda, tangerina, eucalipto, melaleuca, alecrim e laranja, todos estes analisados em cromatógrafo a gás acoplado a detector de massas, para identificação dos principais componentes dos óleos. Foram avaliados o crescimento micelial, produção e germinação de conídios de $B$. cinerea, com a incorporação do óleo no meio de cultura. Realizou-se ainda uma avaliação de voláteis e a eficiência de óleos em isolado resistente a fungicida. Para cada teste, diferentes óleos apresentaram eficiência, contudo capim limão, palmarosa, canela e menta demonstraram os melhores efeitos em todos os testes realizados. Todos os tratamentos a base de óleos demonstraram efeito semelhante a um fungicida recomendado para a cultura, a base de tiofanato metílico. Dois tratamentos mostraram-se efetivos no caso de isolado resistente (óleo de capim limão e de canela). Óleos essenciais mostram-se como opção promissora para o desenvolvimento de possíveis produtos fitossanitários para o manejo de doenças em plantas.
\end{abstract}

Palavras-Chave: Fragaria $x$ ananassa Duch. Ex. Rozier, agricultura orgânica, resistência a fungicidas, controle biológico, óleos essenciais, Botrytis cinerea.

\begin{abstract}
Essential oils bioactivity in strawberry grey mould control. This study aimed evaluates essential oils in Botrytis cinerea isolates growth, which causes gray mould on strawberry. Were tested essential oils of lemon grass, palmrose, citronella, clove, cinnamon, mint, lavender, tangerine, eucalyptus, tea tree, rosemary and orange. The oils were analyzed in gas chromatograph attached to mass detector for identifying the mainly oils components. Were evaluated mycelial growth, conidia production and conidia germination of $B$. cinerea, with oil incorporation in culture medium. Were conducted an evaluation of oils volatile components and the efficiency of oils in fungicide-resistant isolate. For each test, different oils showed efficiency, however lemongrass, palmarosa, cinnamon and mint showed the best effects in all tests. All treatments demonstrated similar effects to recommended fungicide for the culture, which had methyl thiophanate. Two treatments (lemon grass and cinnamon oils), were effective against resistant isolate. Essential oils are shown as promising option for development of possible product for plant disease management.
\end{abstract}

Keywords: Fragaria x ananassa Duch. Ex. Rozier, organic agriculture, fungicide resistance, biological control, essential oil, Botrytis cinerea.

\section{INTRODUÇÃO}

A produção mundial de morango, em 2009,

foi de 4.178.152 toneladas em uma área de 254.523

ha (FAO, 2011). Para o Brasil existem poucas

informações disponíveis quanto à produção. Contudo,

estima-se que a produção nacional esteja em torno de 105 mil toneladas, em 4 mil hectares. Minas Gerais é o maior produtor nacional de morangos, segundo o Instituto Brasileiro de Frutos (IBRAF), com cerca de

Recebido para publicação: agosto de 2011

Aceito para publicação: dezembro de 2011

Rev. Bras. Pl. Med., Botucatu, v.13, especial, p.619-627, 2011. 
40 mil toneladas/ano, o equivalente a $40 \%$ da produção nacional, seguido por São Paulo com 29 mil tonelada/ano e depois, Rio Grande do Sul, Santa Catarina, Paraná, Espírito Santo e Rio de Janeiro, respectivamente (Antunes, 2010). O Sul de Minas Gerais destaca-se, contando com os principais municípios produtores, Pouso Alegre com uma área de 300 ha, Estiva, com 250 ha e Bom Repouso, 240 ha (Carvalho, 2006).

Além da questão econômica para a região, no contexto social a cultura apresenta notável importância, por ser basicamente uma atividade ligada à agricultura familiar. Torna-se, assim, fonte de emprego e renda para famílias inteiras nas regiões produtoras (Camargo Filho \& Camargo, 2009).

Um dos grandes problemas relacionado à cultura é seu manejo, principalmente pela presença significativa de doenças fúngicas, associada ao reduzido número de produtos registrados. Destas doenças o mofo cinzento, causado pelo fungo Botrytis cynerea, destaca-se por acometer o morango desde o campo até a pós-colheita (Simon et al., 2005).

Para o controle destas doenças, as aplicações de fungicidas são feitas, na maioria das vezes, de maneira incorreta e excessiva, ocasionando problemas de contaminação, além de resistência de fungos a determinados princípios ativos (Ghini \& Kimati, 2002).

Com o aumento da demanda por produtos rastreáveis e de maior qualidade, consequentemente com maior valor agregado, novas tecnologias são necessárias para que o manejo fitossanitário possa ser feito de uma forma menos agressiva, tanto em termos ambientais quanto econômicos e sociais (Dayan et al., 2009). Em cultivos orgânicos, uma tendência em expansão, novos produtos são desejados para atender as necessidades impostas pelas atuais normas de controle fitossanitário. Contudo, o avanço da agricultura orgânica esbarra na falta de subsídios advindos de pesquisas mais elaboradas no manejo dessas doenças.

Assim, o emprego de produtos alternativos mostra-se como uma opção viável, dentre estes produtos enquadram-se os óleos essenciais de plantas medicinais e aromáticas (Stangarlin, 2007). Estes óleos apresentam constituintes complexos e variáveis, como hidrocarbonetos terpênicos, álcoois simples e terpênicos, aldeídos, cetonas, fenóis, ésteres, éteres, óxidos, peróxidos, furanos, ácidos orgânicos, lactonas, cumarinas e compostos de enxofre, dentre os quais se destacam os de baixo peso molecular, como os monoterpenos e sesquiterpenos (Simões \& Spitzer, 2000).

Vários são os trabalhos demonstrando a efetividade da ação de óleos essenciais no controle de doenças de plantas. Ranashinge et al. (2002) testando o óleo essencial de cravo comprovaram sua ação antifúngica contra fungos de pós-colheita isolados de banana, Lasiodiplodia theobromae, Colletotrichium musae e Fusarium proliferatum. Anaruma et al. (2010) testando 28 óleos essenciais, constataram a atividade de 15 deles contra Colletotrichum gloeosporioides (Penz.) Sacc., agente da antracnose em maracujá-amarelo (Passiflora edulis Sims f. flavicarpa Deg). Dos óleos testados, o de capim-limão apresentou desempenho semelhante aos fungicidas. Óleos ricos em eugenol, como é o caso do óleo de cravo, mostraram-se eficientes no controle de diversos patógenos pós-colheita de frutas, dentre eles Botrytis cinerea, isolado de uva (Combrinck et al., 2011). Óleos essenciais de plantas da família Lamiaeceae, orégano (Origanum syriacum L. var. bevanii), lavanda (Lavandula stoechas L. var. stoechas) e alecrim (Rosmarinus officinalis L.), demonstraram efeito no controle de $B$. cinerea em tomateiro, sendo o óleo de orégano o mais eficiente (Soylu et al, 2010).

Considerando a importância da cultura do morango e a necessidade do estabelecimento de formas de controle alternativas, objetivou-se avaliar o uso de óleos essenciais de plantas medicinais e aromáticas no controle de mofo cinzento do morangueiro.

\section{MATERIAL E MÉTODO}

O trabalho foi realizado no laboratório de Epidemiologia e Controle de Doenças de Plantas do Departamento de Fitopatologia (DFP) e na Central de Análise e Prospecção Química do Departamento de Química (DQI), ambos localizados na Universidade Federal de Lavras (UFLA), em Lavras - MG.

\section{Obtenção dos óleos essenciais e identificação de componentes químicos}

Os óleos essenciais empregados nos experimentos foram, segundo a família botânica ao qual pertencem: Família Lamiaceae - alecrim (Rosmarinus officinalis), menta (Mentha pipertita), lavandim (Lavandula hybrida); Família Lauraceae tea tree (Melaleuca alternifolia); Família Myrtaceae canela (Cinnamomum zeilanicum), cravo (Syzigium aromaticum), eucalipto (Corymbia citriodora); Família Poaceae - citronela (Cymbopogon nardus), capim limão (Cymbopogon citratus) e palmarosa (Cymbopogon martini) e Família Rutaceae - Iaranja doce (Citrus sinensis var. dulcis), tangerina (Citrus nobilis var. tangerinae). Todos os óleos foram adquiridos da empresa Florananda Indústria e Comércio de Cosméticos e Produtos Naturais, localizada no município de Jaú, Estado de São Paulo.

A análise fitoquímica dos óleos para identificação dos componentes foi feita em cromatógrafo a gás acoplado a detector de massas (GCMS-QP2010 Plus, Shimadzu). O cromatógrafo

Rev. Bras. PI. Med., Botucatu, v.13, especial, p.619-627, 2011. 
gasoso utilizou o hélio ultrapuro como gás de arraste com fluxo de 1,8mL. $\mathrm{min}^{-1}$, temperatura do injetor em $220^{\circ} \mathrm{C}$, modo de injeção Split de 1:15, injeção manual, tempo de corrida estabelecido em 70 minutos, em coluna Equily-5 (30 m x 0,25 mm x 0,25 $\mu \mathrm{m})$, com forno da coluna, a $60^{\circ} \mathrm{C}$, por 2 minutos, aquecimento a $3^{\circ} \mathrm{C} . \mathrm{min}^{-1}$ até $240^{\circ} \mathrm{C}$, permanecendo em $240^{\circ} \mathrm{C}$ por 15 minutos. $O$ espectrômetro de massas utilizou a interface GC-MS, a $250^{\circ} \mathrm{C}$, com fonte de íons a $200^{\circ} \mathrm{C}$ e modo de ionização por impacto de elétrons a $70 \mathrm{eV}$. Os componentes dos óleos essenciais foram identificados mediante comparação dos índices de similaridade de espectro de massa (áreas relativas em porcentagem) apresentados com os dados disponíveis na biblioteca do próprio cromatógrafo (FFNSC 1.2).

\section{Obtenção dos isolados de $B$. cinerea}

Os isolados patogênicos de $B$. cinerea foram obtidos a partir de isolamento direto de estruturas fúngicas de pseudofrutos de morangueiro infectados, coletados em área experimental do Setor de Olericultura - Departamento de Agricultura (DAG) da UFLA e em área de cultivo comercial no município de Tocos do Moji - MG. Para o isolamento, estruturas fúngicas presentes nos pseudofrutos coletados foram transferidas para placas de Petri contendo meio de cultura BDA (Batata Dextrose e Ágar) com o auxílio de microscópio esteroscópio. Seis isolados purificados foram mantidos em câmaras de crescimento do tipo BOD, a $23{ }^{\circ} \mathrm{C}$ e sob fotoperíodo de 12 horas. Para avaliação da patogenicidade, pseudofrutos de morangueiro previamente higienizados em água corrente e desinfestados com hipoclorito de sódio a $2 \%$ ( $\mathrm{NaClO} 2 \%$ ) e água destilada foram inoculados, através de suspensão de esporos, com os isolados obtidos e mantidos em temperatura ambiente em recipientes plásticos, semelhantes aos utilizados para comercialização. Posteriormente foi observada a presença e severidade de sintomas das doenças causadas pelos patógenos. Dos isolados obtidos, um mostrou-se resistente a fungicida à base de tiofanato metílico, sendo empregado em um dos experimentos. Dentre os outros isolados escolheuse um com patogenicidade alta para a realização dos demais experimentos.

\section{Bioatividade de óleos essenciais no crescimento micelial, produção de conídios e germinação de conídios de $B$. cinerea}

Para os testes de crescimento micelial dos patógenos, foram empregados os óleos essenciais de capim-limão, palmarosa, citronela, cravo, canela, menta, lavanda, tangerina, eucalipto, melaleuca, alecrim e laranja; nas concentrações de 125 e $1000 \mathrm{ppm}$. Estas concentrações foram escolhidas baseadas em experimentos anteriores, sendo 125ppm a menor concentração que apresentou algum efeito e 1000ppm uma concentração efetiva para controle do patógeno em questão. Os óleos essenciais foram incorporados ao meio de cultura BDA fundente $\left(50^{\circ} \mathrm{C}\right)$ juntamente com o agente surfactante Tween 20 $(0,05 \mathrm{~mL})$.

Como tratamento testemunha, foi utilizada uma placa de Petri contendo apenas o meio de cultura. E para efeito de comparação, adotou-se um padrão químico considerado eficiente no combate dos patógenos, representado por um fungicida a base de tiofanato metílico, incluído ao meio de cultura na dose 1000ppm.

$\mathrm{Na}$ avaliação do crescimento micelial, colocou-se um disco de $9 \mathrm{~mm}$ de diâmetro do micélio da cultura pura do patógeno no centro de cada placa. O delineamento experimental foi inteiramente casualizado, com três repetições por tratamento, sendo cada unidade experimental composta por uma placa de Petri. As placas foram acondicionadas em câmara de crescimento do tipo BOD à $23^{\circ} \mathrm{C}$. Realizouse a medição do diâmetro das colônias, em posição ortogonal a cada 24 horas até que o tratamento atingisse o diâmetro total da placa de Petri. Os valores obtidos foram utilizados para o cálculo do "Índice de Velocidade de Crescimento Micelial", através da equação:

$$
\text { IVCM }=\frac{\boldsymbol{\Sigma}(d-d a)}{\mathrm{N}}, \text { na qual: IVCM }=\text { Índice }
$$

de Velocidade de Crescimento Micelial, $\mathrm{D}=$ diâmetro médio atual da colônia, $\mathrm{Da}=$ diâmetro médio da colônia do dia anterior, $\mathrm{N}=$ número de dias após a inoculação.

A produção de conídios foi avaliada após o total crescimento do patógeno nas placas de Petri. Em cada placa adicionou-se $20 \mathrm{~mL}$ da solução água destilada e Tween 20 autoclavados. A superfície da colônia foi raspada com auxílio de Alça de Drigalski. Os esporos de cada placa foram filtrados em gaze e acondicionados em béquer. Para cada suspensão de esporos, quatro alíquotas de $0,1 \mathrm{~mL}$ foram transferidas, separadamente, para uma lâmina de hemacitômetro, na qual foi realizada a contagem de esporos através do emprego de microscópio óptico. Os dados médios de quatro contagens foram considerados segundo a quantidade de conídios produzidos na área total de cada placa de Petri. O delineamento experimental foi inteiramente casualizado, com quatro repetições por tratamento, e a unidade experimental composta por uma contagem efetuada no hemacitômetro.

A taxa de germinação foi avaliada realizando a contagem de esporos germinados do patógeno. Os óleos essenciais na concentração 1000ppm foram misturados ao agente dispersante Tween $20(0,05 \mathrm{~mL})$ e incorporados ao meio de cultura ágar-água em 
placas de Petri. Paralelamente, uma suspensão de esporos do patógeno foi elaborada e disposta em gotas sobre o meio de cultura. Estes esporos foram obtidos através de raspagem de colônia do patógeno crescida em placa de Petri por sete dias, sendo os esporos transferidos para um béquer contendo água destilada estéril. Na inoculação, foram utilizadas gotas de $20 \mu \mathrm{L}$ da suspensão de conídios, dispostas sobre o meio de cultura. Após a inoculação, as placas permaneceram em temperatura de $23^{\circ} \mathrm{C}$ por 24 horas, sendo então avaliadas. Realizou-se a contagem de 50 conídios, por repetição, com auxílio de microscópio óptico para a avaliação da porcentagem de germinação. $O$ delineamento experimental foi inteiramente casualizado, com quatro repetições por tratamento.

\section{Bioatividade de componentes voláteis de óleos essenciais no crescimento micelial, produção de conídios e germinação de conídios de $B$. cinerea}

Os mesmos óleos essenciais (capim-limão, palmarosa, citronela, cravo, canela, menta, lavanda, tangerina, eucalipto, melaleuca, alecrim e laranja) foram dispostos sobre papéis de filtro $(0,5 \mathrm{~cm}$ de diâmetro) em três pontos equidistantes sobre o meio de cultura BDA vertido previamente em placas de Petri. Em cada ponto colocou-se uma alíquota de $5 \mu \mathrm{L}$, totalizando $15 \mu \mathrm{L}$ por placa de Petri.

Após a aplicação dos óleos essenciais, no centro de cada placa foi inserido um disco de $9 \mathrm{~mm}$ de diâmetro do micélio da cultura pura do patógeno. $O$ delineamento experimental foi inteiramente casualizado, com três repetições por tratamento, sendo cada unidade experimental composta por uma placa de Petri. As placas foram acondicionadas em câmara de crescimento do tipo BOD à $23^{\circ} \mathrm{C}$. Mediuse o diâmetro das colônias, em posição ortogonal a cada 24 horas até que o tratamento atingisse 0 diâmetro total da placa de Petri. Os valores obtidos foram utilizados para o cálculo do "Índice de Velocidade de Crescimento Micelial".

\section{Análises estatísticas}

Os valores obtidos nos tratamentos foram submetidos à análise de variância e transformados quando necessário, sendo submetidos ao teste de Duncan (pd"0,05) através do programa computacional SAS (SAS INSTITUTE, 2002).

Bioatividade dos óleos essenciais de capim limão e canela no crescimento micelial de isolado resistente de $B$. cinerea

A partir dos resultados anteriores, selecionouse dois óleos essenciais (capim-limão e canela) eficientes na redução do crescimento micelial do patógeno ( $B$. cinerea) para a avaliação em isolado resistente ao princípio ativo tiofanato metílico obtido no município de Tocos do Moji - MG.

O experimento seguiu a mesma metodologia, no qual os óleos foram incorporados ao meio de cultura. Contudo, foram testadas as concentrações de $125,250,500$ e 1000ppm para os dois óleos. O delineamento experimental foi inteiramente casualizado, com três repetições por tratamento, sendo cada unidade experimental composta por uma placa de Petri. Os valores obtidos nos tratamentos foram submetidos à análise de regressão através do programa computacional SAS (SAS INSTITUTE, 2002).

\section{RESULTADO E DISCUSSÃO}

Os óleos essenciais foram selecionados com base na literatura especializada. Nestes óleos detectou-se mais de 50 compostos, dos quais os cinco principais de cada óleo são apresentados na tabela 1. Alguns óleos (cravo, canela e tangerina) apresentaram componente majoritário.

O efeito fungistático e fungicida apresentados pelos óleos em estudo podem estar relacionado á presença de componentes majoritários. Óleos essenciais podem conter componentes químicos em diferentes concentrações, geralmente um composto majoritário e outros em menor quantidade (Simões \& Spitzer, 2000). Componentes majoritários, como o citral e o eugenol, mostram efeito fungicida semelhante a óleos que possuem em sua composição tais compostos (Combrinck et al., 2011).

A partir das análises dos óleos essenciais, neste estudo, com exceção de tangerina e laranja doce, os óleos que apresentaram destaque para componentes majoritários apresentaram maior atividade. Tangerina e laranja doce, cujo constituinte majoritário foi o limoneno, não demonstraram controle para os patógenos testados. Confirmando que o limoneno, não apresenta boa atividade fungicida ou fungistática em alguns patossistemas mesmo como composto purificado (Rozwalka, 2010; Combrinck et al., 2011).

A eficácia de outros óleos que não apresentaram componente majoritário, como é o caso de citronela, deve-se ao efeito sinergístico entre os componentes do óleo essencial, levando a efetividade no controle de microorganismos (Combrinck et al., 2011).

Capim limão e palmarosa pertencentes à mesma família botânica - Poaceae apresentam monoterpenóides semelhantes em sua composição, demonstrando controle de $B$. cinerea. Considerando estes monoterpenóides como componentes majoritários destas espécies, o geraniol e citral, é possível que a ação fungicida apresentada esteja relacionada à estes constituintes químicos.

Rev. Bras. PI. Med., Botucatu, v.13, especial, p.619-627, 2011. 
TABELA1. Porcentagem de área de componentes majoritários de óleos essenciais, separados segundo família botânica, identificados em cromatógrafo a gás acoplado a detector de massas (GCMS-QP2010 Plus, Shimadzu). UFLA - Lavras - MG, 2011.

\begin{tabular}{|c|c|c|c|c|c|c|}
\hline Nome vulgar & Nome Científico & Componente Majoritário & $2^{\circ}$ Componente & $3^{\circ}$ Componente & $4^{\circ}$ Componente & $5^{\circ}$ Componente \\
\hline \multicolumn{7}{|l|}{ Poaceae } \\
\hline Capim-limão & Cymbopogon citratus & Geranial $(38,67 \%)$ & Neral $(32,40 \%)$ & Myrcenn $(13,88 \%)$ & Geraniol $(2,79 \%)$ & Verhenol $(1,32 \%)$ \\
\hline Citroncla & Cymbopogon nardus & Citronclal $(23,7 \%)$ & Gcraniol $(16,48 \%)$ & Oct 7 cnol $(13,14 \%)$ & Elcmol $(5,14 \%)$ & Citronclil isobutirato $(4,89 \%)$ \\
\hline Palmarosa & Cymbopogon martini & Geraniol $(73,86 \%)$ & Geranil Acetato $(27,65 \%)$ & Linalol $(12,14 \%)$ & E - $\beta$-Ocimene $(3,77 \%)$ & a-Himachalene $(1,46 \%)$ \\
\hline \multicolumn{7}{|l|}{ Myrtaceae } \\
\hline Eucalipto & Corymbia citriodora & Citronelal $(30,45 \%)$ & Oct-7-enol $(15,23 \%)$ & Isopulegol (13,83\%) & Fenchyl acetato $(8,43 \%)$ & Eucaliptol $(2,71 \%)$ \\
\hline Melaleuca & Melaleuca alternifolia & Terpinen-4-nl $(26,64 \%)$ & $y$ terpineno $(8,81 \%)$ & Fucaliptol (5,67\%) & a terpinenn $(6,07 \%)$ & Cimeno $(5,45 \%)$ \\
\hline Cravo & Syzigium aromaticum & Eugenol $(77,81 \%)$ & a humulcno $(14,56 \%)$ & $\delta$ cadincno $(3,03 \%)$ & Óxido Cariofileno $(1,43 \%)$ & \\
\hline \multicolumn{7}{|l|}{ Lauraceae } \\
\hline Canela & Cinnamomum zeilanicum & Eugenol $(53,38 \%)$ & a himachaleno $(9,44 \%)$ & Biciclogermacreno $(7,61 \%)$ & Linalol $(3,47 \%)$ & Nerolidol $(3,08 \%)$ \\
\hline \multicolumn{7}{|l|}{ Lamiaceae } \\
\hline Menta & Mentha pipertita & Mentol $(38,14 \%)$ & Mentona $(36,96 \%)$ & Menthyl acetato $(7,17 \%)$ & $\alpha$ Himachaleno $(5,36 \%)$ & Eucaliptol $(4,96 \%)$ \\
\hline Lavanda & Lavandula hybrida & Octil Acetato $(21,00 \%)$ & Linalol $(15,03 \%)$ & Isobornil acetato $(11,26 \%)$ & Canfora $(11,16 \%)$ & a Himachaleno $(6,86 \%)$ \\
\hline Alecrim & Rosmarinus officinalis & Eucaliptol $(27,25 \%)$ & Canfora $(21,21 \%)$ & Pineno $(16,68 \%)$ & Canfeno $(9,89 \%)$ & a terpineol $(4,30 \%)$ \\
\hline \multicolumn{7}{|l|}{ Rutaceae } \\
\hline Tangerina & Citrus nobilis var. tangerinae & Limoneno $(97,02 \%)$ & Mirceno $(1,50 \%)$ & Pineno $(0,34 \%)$ & & \\
\hline Laranja & Citrus sinensis var. dulcis & Limoneno (94.13\%) & Mirceno $(3.50 \%)$ & Pineno $(0.68 \%)$ & Caprialdeído $(0.59 \%)$ & Sabineno $(0.47 \%)$ \\
\hline
\end{tabular}

No primeiro ensaio, a menor concentração (125ppm) dos óleos essenciais, incorporados ao meio de cultura, mostrou-se pouco eficiente, contudo demonstrando os primeiros efeitos para os óleos promissores (Figura 1). Na concentração de 125ppm, canela, cravo, palmarosa e capim limão, óleos ricos em eugenol, geraniol e citral (combinação de neral e geranial), apresentaram melhor efeito em relação à testemunha, com 41, 31, 27 e $17 \%$ de controle respectivamente comparado à testemunha. Na maior dose (1000ppm), capim limão e palmarosa apresentaram efeito fungicida ( $100 \%$ de controle), impedindo o crescimento do patógeno. Menta, eucalipto, canela e citronela apresentaram controle satisfatório do crescimento micelial, apresentando controle de 96, 91, 84 e 79\% respectivamente em relação à testemunha. A dose do fungicida a base de tiofanato metílico empregado (1000ppm) apresentou $100 \%$ de controle equiparando-se aos óleos de capim limão e palmarosa e não sendo considerada nas análises.

Em relação à produção de conídios de $B$. cinerea sobre ação de óleos essenciais, capim limão, palmarosa, menta, eucalipto, cravo, canela inibiram completamente a esporulação do fungo (Tabela 2). Apesar de apresentar crescimento micelial, exceto para capim limão e palmarosa, o patógeno não produziu esporos no período avaliado. $\mathrm{O}$ aumento no tempo para produção de estruturas reprodutivas (esporos) é favorável para o controle de doenças (Agrios, 2005).

Wilson et al. (1997) avaliaram a ação antifúngica de 345 extratos de plantas e 49 óleos essenciais sobre Botrytis cinerea. Dentre os óleos testados, palmarosa (Cymbopogon martini), tomilho (Thymus zygis), canela (Cinnamomum zeylanicum) e cravo-da-índia (Syzygium aromaticum) apresentaram melhores resultados na inibição do fungo. Estes resultados corroboram aos obtidos no presente trabalho para o óleo de palmarosa e de canela.
O óleo de cravo mostrou ação antifúngica contra fungos isolados de banana, Lasiodiplodia theobromae, Colletotrichium musae e Fusarium proliferatum (Ranashinge et al, 2002). Neste trabalho, o óleo de cravo mostrou-se eficaz na redução da germinação de conídios, e, semelhante à canela tem como constituinte majoritário o eugenol.

O óleo de capim limão também possui importantes registros quanto à ação fungicida. Nguefack et al. (2004) avaliando o efeito do óleo essencial de capim limão no crescimento micelial de fungos, observaram a redução de $64 \%$ do desenvolvimento de Fusarium moniliforme na concentração de 200 ppm, Aspergilus flavus em 48\% e Aspergilus fumigatus em $77 \%$ na concentração de 500 ppm, além de inibição total em 300 ppm para $F$. moniliforme e $1200 \mathrm{ppm}$ para $A$. flavus e $A$. fumigatus.

Óleos essenciais de canela, capim-limão, cravo, eucalipto, melaleuca e menta apresentaram controle eficiente de Alternaria solani, agente etiológico da pinta-preta do tomateiro, tanto em condições in vitro como em condições de campo (Abreu, 2006). Com exceção do óleo de melaleuca, todos apresentaram eficiência no controle do mofo cinzento. Em trabalho com patógenos de pós-colheita em citrus, o óleo essencial de menta na concentração de 1.000 mg. $\mathrm{L}^{-1}$, inibiu em $36,8 \%$ e $59,44 \%$ o crescimento micelial de Penicillium italicum e Alternaria citri respectivamente (Azizi et al., 2008).

Quanto aos componentes voláteis, avaliados através da aplicação dos óleos essenciais nos papéis de filtro, sem contato direto do óleo com o patógeno, capim limão apresentou $100 \%$ de inibição do crescimento micelial de $B$. cinerea (Figura 2). Canela, melaleuca, menta, eucalipto, cravo e palmarosa apresentaram de 80 a 59\% de controle em relação à testemunha.

Outros trabalhos empregando componentes voláteis no controle de patógenos demonstraram o 


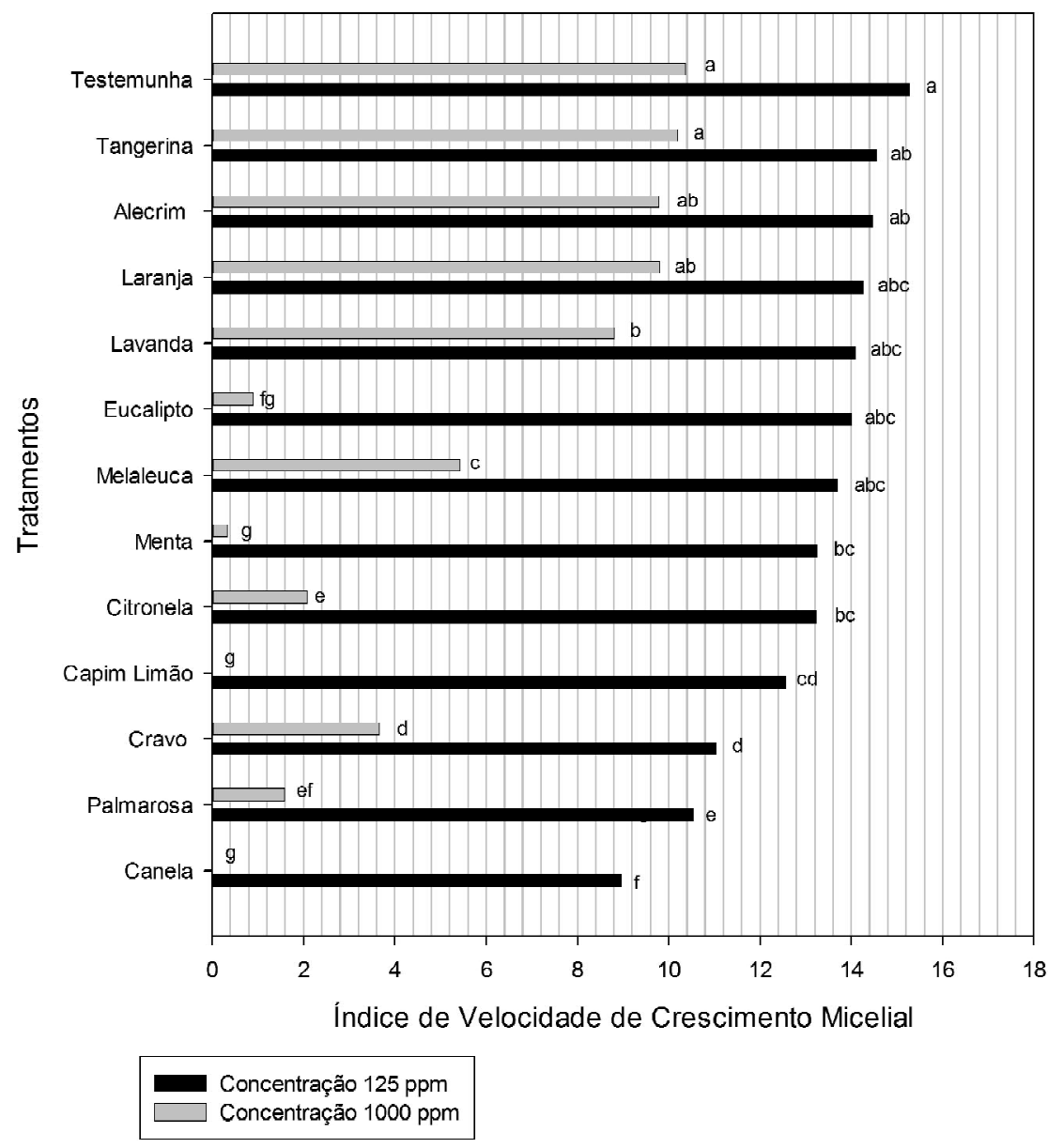

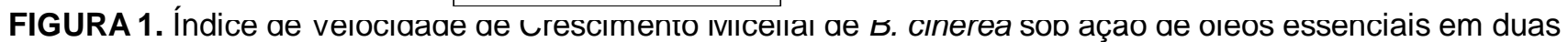
concentrações. UFLA - Lavras - MG, 2011. Barras para cada efeito, com letras minúsculas distintas diferem pelo teste de Duncan $(\mathrm{p} \leq 0,05)$.

TABELA 2. Produção e porcentagem de germinação de conídios de $B$. cinerea sob ação de óleos essenciais. UFLA - Lavras - MG, 2011.UFLA - Lavras - MG, 2011.

\begin{tabular}{crr}
\hline Tratamento & $\begin{array}{c}\text { Produção de } \\
\text { Conídios }\left(\times 10^{6}\right)^{1}\end{array}$ & Germinação $(\%)^{2}$ \\
\hline Canela & $0 \mathrm{f}^{*}$ & $0 \mathrm{c}$ \\
Capim Limão & $0 \mathrm{f}$ & $0 \mathrm{c}$ \\
Cravo & $0 \mathrm{f}$ & $0 \mathrm{c}$ \\
Eucalipto & $0 \mathrm{f}$ & $0,5 \mathrm{c}$ \\
Menta & $0 \mathrm{f}$ & $0 \mathrm{c}$ \\
Palmarosa & $0 \mathrm{f}$ & $0,5 \mathrm{c}$ \\
Citronela & $88,5 \mathrm{e}$ & $1,5 \mathrm{c}$ \\
Laranja & $100,75 \mathrm{de}$ & $98,5 \mathrm{ab}$ \\
Tangerina & $105,5 \mathrm{de}$ & $100 \mathrm{a}$ \\
Testemunha & $113,75 \mathrm{~d}$ & $100 \mathrm{a}$ \\
Alecrim & $137,5 \mathrm{c}$ & $97 \mathrm{~b}$ \\
Melaleuca & $175,75 \mathrm{~b}$ & $1,5 \mathrm{c}$ \\
Lavanda & $377,5 \mathrm{a}$ & $97 \mathrm{~b}$ \\
\hline
\end{tabular}

* Médias seguidas de letras minúsculas distintas nas colunas diferem pelo teste de Duncan $(p \leq 0,05)$.

1 Dados transformados para arc sen $\sqrt{x} / 100{ }^{2}$ Dados transformados para $V_{x}$ 
FIGURA 2. Índice de Velocidade de Crescimento Micelial de $B$. cinerea sob ação de componentes voláteis de óleos essenciais. UFLA - Lavras - MG, 2011. Barras para cada efeito, com letras minúsculas distintas diferem pelo teste de Duncan $(p \leq 0,05)$.

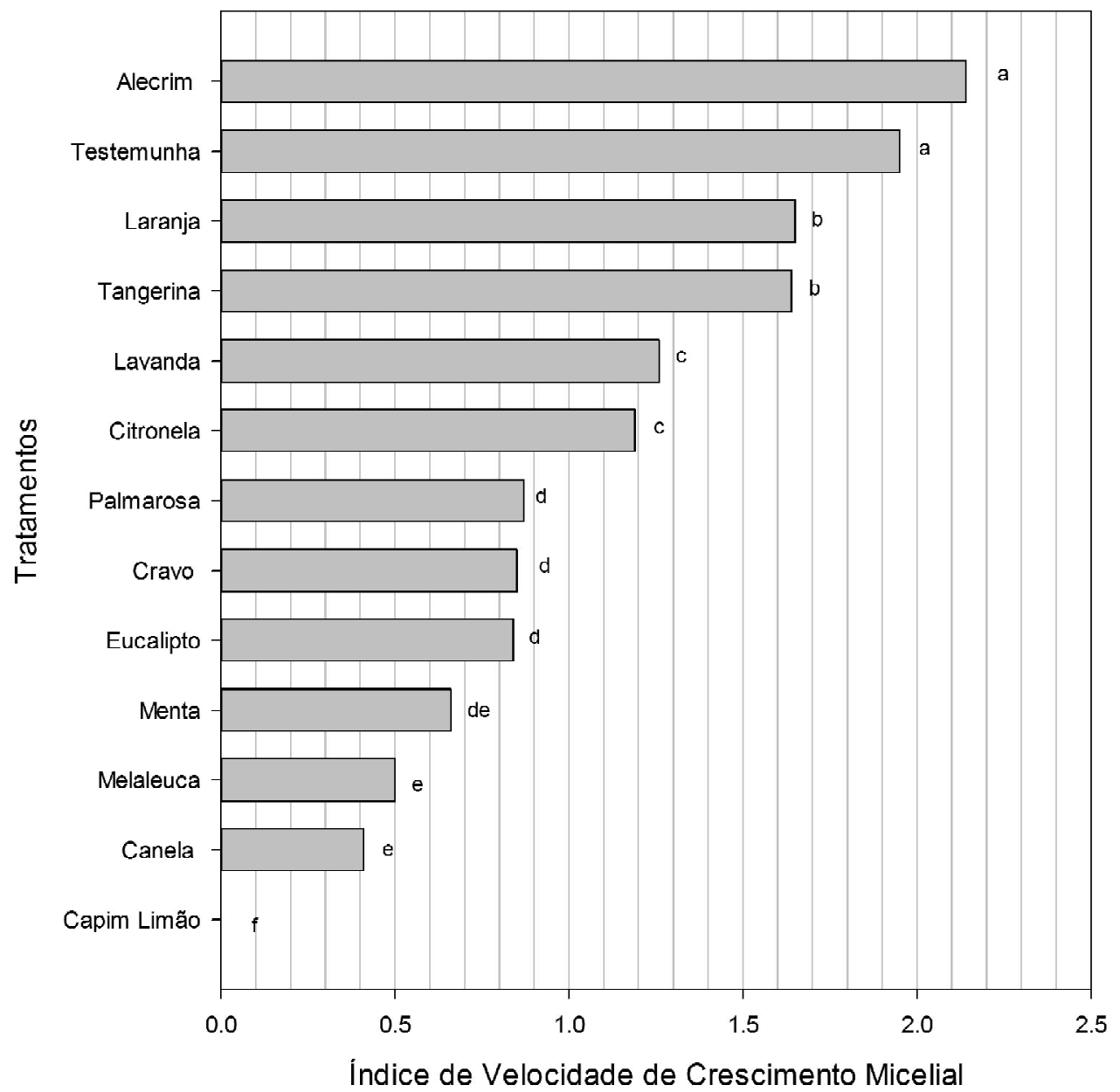

efeito fungicida de óleos essenciais. Componentes voláteis presentes nos óleos essenciais de de tomilho, orégano e capim-limão mostraram inibição total do crescimento de Botrytis cinerea e Alternaria arborescens (Plotto et al., 2003). Os compostos voláteis trans-2-hexenal, carvacrol, trans-cinamaldeído e citral (componente do óleo de capim limão) apresentam expressiva atividade antifúngica sobre 0 crescimento micelial, germinação e esporulação de Penicillium expansum (Neri et al., 2006). Componentes voláteis do óleo essencial de capim -limão proporcionaram redução significativa no desenvolvimento das colônias de Colletotrichum coccodes, Botrytis cinerea, Cladosporium herbarum, Rhizopus stolonifer e Aspergillus Níger, entre 25 e 500 ppm (Tzortzakis \& Economakis, 2007).

Quanto ao isolado resistente, os óleos essenciais testados mostraram eficiência segundo a dose empregada. Na dose de 1000ppm ambos os óleos demonstraram $100 \%$ de controle, inibindo o crescimento do patógeno, apesar de canela não ter apresentado os mesmos resultados para o outro isolado, evidenciando novamente diferenças com relação ao isolado (Figura 3 ).

$B$. cinerea apresenta alto risco de adquirir resistência a fungicidas (Myresiotis et al., 2007), sendo um sério problema em áreas produtoras. Além da questão da resistência de isolados, outro problema é a falta de princípios ativos registrados para uma rotação de agroquímicos (apenas dois químicos e dois biológicos - Agrofit, 2011). Assim, os óleos essenciais constituem nova alternativa para o manejo de doenças nos casos de resistência a fungicidas (Chang et al., 2008).

Além disso, geralmente, os óleos essenciais possuem baixa toxicidade para mamíferos, são biodegradáveis, não persistentes no ambiente, apresentam relativo baixo custo de produção, além de apresentarem atividade inseticida e fungicida (Isman, 2000). Os óleos essenciais de canela, capim limão, palmarosa e menta mostram-se como os mais promissores para estudos futuros para este patossistema. Destes, canela possui como constituinte majoritário o eugenol, capim limão o 

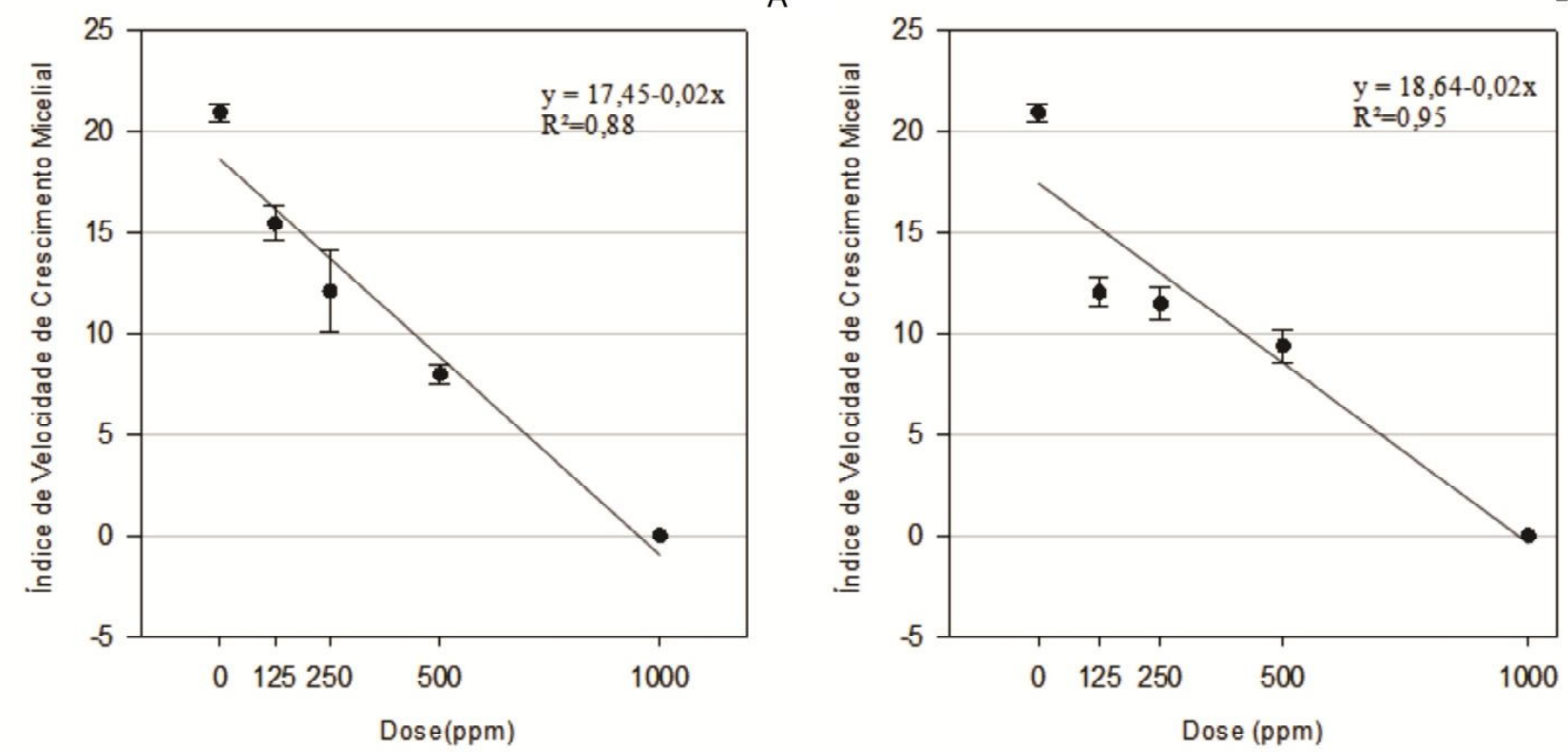

FIGURA 3. Índice de Velocidade de Crescimento Micelial de $B$. cinerea sob ação dos óleos essenciais de canela (A) e capim limão (B) em diferentes concentrações. UFLA - Lavras-MG, 2011.

citral, palmarosa o geraniol e menta o mentol.

A identificação de componentes oriundos do metabolismo secundário de plantas, presentes nos óleos essenciais, que exercem efeito no controle de doenças, torna-se uma ferramenta auxiliar a indústria química quanto à prospecção de novos produtos. Igualmente, com o avanço da agricultura orgânica e as exigências do mercado consumidor por produtos oriundos de práticas agrícolas menos agressivas, os óleos essenciais podem atender esta demanda, fornecendo subsídios para o manejo de doenças quando necessário.

\section{AGRADECIMENTO}

Ao Cnpq, à Capes, à Fapemig pela concessão de bolsas de estudo para os autores. A Central de Análise e Prospecção Química do Departamento de Química da Universidade Federal de Lavras (UFLA) pela disponibilização da estrutura, pessoal e dos equipamentos para realização das análises fitoquímicas dos óleos essenciais.

\section{REFERÊNCIA}

ABREU, CLM. Controle de Alternaria solani em tomateiro (Lycopersicun esculentum) com óleos essenciais. 2006. 71f. Tese (Doutorado em Agronomia - Horticultura) - Departamento de Produção Vegetal, UNESP - Faculdade Ciências Agronômicas, Botucatu. AGRIOS, G.N. Plant Pathology. 5. ed. London, UK: Elvesier Academic Press. 2005. 530 p.

AGROFIT - MINISTÉRIO DAAGRICULTURA, PECUÁRIA
E ABAStECIMENTO. Sistema de Agrotóxicos Fitossanitários, 2011 Disponível em: < http:// agrofit.agricultura.gov.br/agrofit_cons/ principal_agrofit_cons>. Acesso em: 28 ago. 2011.

ANARUMA, N. D. et al. Control of Colletotrichum gloeosporioides (Penz.) Sacc. in yellow passion fruit using Cymbopogon citratus essential oil. Brazilian Journal of Microbiology, v. 41, n. 1, p. 66-73, 2010. ANTUNES, L. E. C. Panorama da produção de morango no Brasil. Revista Campo \& Negócios HF. Ano VII, v. 69, n.91 p, 2010.

AZIZI, M. et al. Inhibitory effect of some medicinal plants' essential oils on postharvest fungal disease of citrus fruits. In: International Horticultural Congress, 27., 2006, Belgium. Anais... Belgium: Acta Horticulturae, 2008. p. 279-286.

CAMARGO FILHO, W.P.; CAMARGO, F.P. Análise da produção de morango dos Estados de São Paulo e Minas Gerais e do mercado da Ceagesp. Informações Econômicas, v.39, n.5, p. 42-50, 2009.

CHANG, H.T. et al. Antifungal activity of essential oil and its constituents from Calocedrus macrolepis var. formosana Florin leaf against plant pathogenic fungi. Bioresource Technology, v.99, art. 14, p. 6266-70, 2008. COMBRINCK, S.; REGNIER, T.; KAMATOU,G.P.P. In vitro activity of eighteen essential oils and some major components against common postharvest fungal pathogens of fruit. Industrial Crops and Products, v.33, p. 344-9, 2011.

DAYAN, F.E.; CANTRELL, C.L.; DUKE, S.O. Natural products in crop protection. Bioorganic \& Medicinal Chemistry, v.17, n.12, p.4022-342, 2009.

DUARTE FILHO, J. Cultivares de morango. In: CARVALHO, S. P. (Coord.). Boletim do morango: cultivo convencional, segurança alimentar e cultivo orgânico, Belo Horizonte: FAEMG, 2006, p. 15-22.

FAO. Dados agrícolas de FAOSTAT, Disponível em http:/ 
/faostat.fao.org/site/567/DesktopDefault.aspx? PagelD=567\#ancor Acesso em: 25 ago. 2011.

GHINI, R.; KIMATI, H. Resistência de fungos a fungicidas. Jaguariúna: Embrapa Meio Ambiente, 2002. 78 p.

ISMAN, M.B. Plant essential oils for pestand disease management. Crop Protection, v.19, 2000, p.603-8. MYRESIOTIS, C.K.; KARAOGLANIDIS, G.S.; TZAVELLAKLONARI, K. Resistance of Botrytis cinerea isolates from vegetable crops to anilinopyrimidine, phenylpyrrole, hydroxyanilide, benzimidazole, and dicarboximide fungicides. Plant Disease, v.91, n.4, p. 407-13, 2007. NERI, F.; MARI, M.; BRIGATI, S. Control of Penicillium expansum by plant volatile compounds. Plant Pathology, v. 55, n. 1, p. 100-5, 2006.

NGUEFACK, J. et al. Evaluation of five essential oils from aromatic plants of Cameroon for controlling food spoilage and mycotoxin producing fungi. International Journal of Food Microbiology, v. 94, n.3, p. 329-34, 2004. PLOTTO, A.; ROBERTS, D.D.; ROBERTS, R.G. Evaluation of plant essential oils as natural postharvest disease control of tomato (Lycopersicon esculentum). Acta Horticulturae, v. 628, p. 737-45, 2003.

RANASINGHE, L.; JAYAWARDENA, B.;ABEYWICKRAMA, K. Fungicidal activity of essential oils of Cinnamomum zeylanicum (L.) and Syzygium aromaticum (L.) Merr et L.M.Perry against crown rot and anthracnose pathogens isolated from banana. Letters in Applied Microbiology, v. 35, n.3, p. 208-11, 2002.

ROZW ALKA, L.C. Óleos essenciais: ação sobre Colletotrichum gloeosporioides e Colletotrichum musae, associados ou não à película de fécula de mandioca no controle da antracnose em goiaba. 2010, 198f. Tese (Doutorado em Agronomia - Fitopatologia) -
Departamento de Fitopatologia, Universidade Federal de Lavras, Lavras.

SAS INSTITUTE. SAS/STAT: user's guide. version 9.0, Cary, 2002.

SIMÕES, C. M. O.; SPITZER, V. Óleos voláteis. In: SIMÕES. C. M. O. et al. Farmacognosia: da planta ao medicamento. 2. ed. Porto Alegre: Universidade Federal do Rio Grande do Sul e Universidade Federal de Santa Catarina, 2000. p. 394-412.

SIMON, N.; MENEGUZZO, A.; CALGARO, A. Doenças causadas por fungos e bactérias In: SANHUEZA, R.M.V. et al. Sistema de produção de morango para mesa na região da serra gaúcha e encosta superior do Nordeste. Bento Gonçalves: Embrapa Uva e Vinho. (Sistema de Produção, 6). Disponível em: http:// ww w. cnpuv. embrapa.br/publica/sprod/ MesaSerraGaucha/. Acesso em: 20 de julho de 2011. SOYLU, E.M.;KURT, S.; SOYLU, S. In vitro and in vivo antifungal activities of the essential oils of various plants against tomato grey mould disease agent Botrytis cinerea, International Journal of Food Microbiology, v. 143, p. 183-9, 2010.

STANGARLIN, J. R. Uso de extratos e óleos essenciais no controle de doenças de plantas - Fitopatologia Brasileira, v. 32 suplemento, p. 94- 6, 2007.

TZORTZAKIS N. G.; ECONOMAKIS, C. D. Antifungal activity of lemongrass (Cympopogon citratus L.) essential oil against key postharvest pathogens. Innovative Food Science e Emerging Technologies, v. 8, n. 2, p. 253- 8, 2007.

WILSON, C. L. et al. Rapid evaluation of plant extracts and essential oils of antifungal activity against Botrytis cinerea, Plant Disease, v. 81, n.2, p. 204-210, 1997. 